\title{
Northern and Southern Moche: The Stylistic Distinctions of Face-Neck Vessels Across Regions
}

\author{
Shannon Marie Trono \\ College of the Arts, University of Florida \\ Faculty mentor: Maya Stanfield-Mazzi, School of Art + Art History
}

\begin{abstract}
This essay is an investigation of stylistic differences in the ceramic production of "face-neck" vessels from the Middle Moche Period (400-600 CE) of the Northern and Southern Moche regions. These faceneck vessels are also referred to as effigy vessels or cántaros cara gollete in Andean ceramic classifications. Face-neck vessels take the shape of human bodies where the torso and limbs have been condensed into a large globular mass; on the neck (the spout of the vessel) appears a human face in relief. The focus of this paper is fineware face-necks rather than utilitarian wares since the majority of the vessels in this discussion originate from monumental funerary complexes for the elite. Face-neck vessels were commonly used to hold liquids like corn beer, which was consumed in ceremonial practices. By comparing vessels produced contemporaneously by Northern and Southern Moche polities, a set of distinctions regarding form, surface decoration, and finishing techniques appear to distinguish each group. Using these distinctions, an argument is made that the two face-neck vessels from the Harn Museum of Art, which have an unknown provenience, originate from the Southern Moche region between stages III and IV in the Moche ceramic sequence. In the process, this paper discusses burial practices, the concept of dualism in Moche culture, and the significance of mold technology (with implications for Moche funerary practice). While this research relies heavily on the external observation of effigy vessels, ceramicist knowledge and experience provide meaningful insight on production processes and are crucial to developing stylistic characteristics for each group.
\end{abstract}

Keywords: Moche, ceramics, effigy vessels, face-neck

\section{Introduction}

The Moche civilization developed in the Pre-Hispanic North Coast of Peru during 100-800 CE and was divided by the Sechura Desert into two zones, the Northern Moche and the Southern Moche. In the Middle Moche period (300-600 CE) also known as the Florescent period, the Northern Moche people occupied the Piura, Lambayeque, and Jequetepeque Valleys, distinguished by the sites of Sipán, San José de Moro, Pacatnamú, and Huaca Dos Cabezas, which served as monumental funerary complexes for the elite. The Southern Moche occupied the Chicama, Moche, Virú, Chao, Santa, and Nepeña Valleys, and built the major funerary sites of Huaca Cao Viejo, Huacas de Moche, Huaca de la Cruz, and Pañamarca (Castillo and Donnan 1995). 
In the Middle period, the Moche civilization expanded its territories, spread Moche ideologies, and was ruled not by a single ruler but by many individual polities throughout the North Coast (Castillo and Donnan 1995). While each social group developed independently, it was likely that they formed alliances and peer-polity interactions. The relative separation between the Northern and the Southern polities led to the development of different styles and techniques in craft production, albeit with a shared iconography that suggests the Northern and Southern Moche shared common religious beliefs expressed through rituals of battle, sacrifice, and funerary practice (Chicoine 2011).

Our understanding of the Moche culture has developed through analysis of the wealth of material culture the Moche left behind-particularly their abundant ceramics. Ceramics function as a transmitter of messages, "Potters worked with earth, water, fire and air, and they transformed shapeless, malleable material into objects that could serve various purposes and could represent the most diverse things and living creatures" (Holmquist 2013, 68). While extensive research has been conducted on the sequential development of the stirrup-spout vessel as well as its distinctions across the Northern and Southern regions, there are many other vessel forms that have been neglected. The face-neck vessel is an example of a form that has been overlooked in both Moche and the wider span of Andean art.

When searching for images of face-neck vessels on the internet, results will erroneously display images of portrait vessels, a well-studied Moche type in which a portrait-like face forms the chamber of a vessel rather than its spout (Donnan 2003). It is evident that formal distinctions in the face-neck form have not been established. Nor has the style of Northern and Southern face-necks been clearly articulated. Beyond establishing definitive information for the two Harn vessels, this analysis can serve as a reference tool for categorizing other face-neck vessels. This will help future researchers, museum curators, and registrars who are unfamiliar with the regional pottery differences. In addition, this paper provides a basis for understanding Moche ceramic production and culture.

\section{Methodology}

The art historical methods of formal, iconographic, and technical analysis on the comparative ceramic samples from the North and South regions. Formal analysis looks at basic design elements such as color, space, texture, and proportions, identifying differences in style that distinguish the approaches of North and South, especially in regard to conveying depth and 
three-dimensionality. Iconographic analysis is used to trace prevalent themes including warfare, death, and sacrifice. Technical analysis of the Moche artist/s techniques, tools, and materials to better understand their ceramic production process is investigated. Finally, interpretations of existing art historical writing and archaeological field reports on the subject are developed.

\section{Origins of Comparative Samples}

The Northern face-neck vessels referenced in this paper are either sourced from the site of San José de Moro, a northern Moche settlement, or are currently at the Fowler museum. Although their provenience is unknown, the vessels from the Fowler are of the same style as various vessels from Sipán (Alva and Donnan 1994, Fig. 49, 50, 51), another northern site.

The Southern face-neck vessels referenced in this paper are sourced from the Larco Museum and the Fowler Museum. The majority of the Larco Museum collection originates from the Chicama Valley, which is in the Southern region (Koons 2012, 389). The vessels from the Fowler Museum visually parallel several Southern vessels from the Southern Larco collection. While none of the Fowler pieces have an exact provenience identified, their online collection has high-quality photos of each vessels in various angles.

\section{Northern Moche Ceramics in the Middle Period}

The splendor of North Moche is best preserved in exquisite metallurgy found at the opulent tombs of Sipán and the complex fine-line painted narratives on stirrup-spout vessels found in abundance at the ceremonial funerary complex of San José de Moro. The North Moche particularly excelled in metalworking -creating mixed-media items using precious metals, gemstones, and spondylus shells. Metallurgy may have been the preferred visual method by which the Northern elites transmitted Moche ideology in order to establish identity and social hierarchy (Castillo and Uceda 2008).

Yet Jackson $(2008,39)$ states, "Complex tombs of extremely high-status individuals, like those at Sipán and San Jose de Moro, included literally hundreds, or even thousands, of ceramic vessels, [along with] human and animal sacrifices, fine jewelry, and ornate textiles". These exuberant burials exemplified the diverse artistic skillsets of Northern Moche craftsmen and demonstrated their strength in working with a variety of materials. 


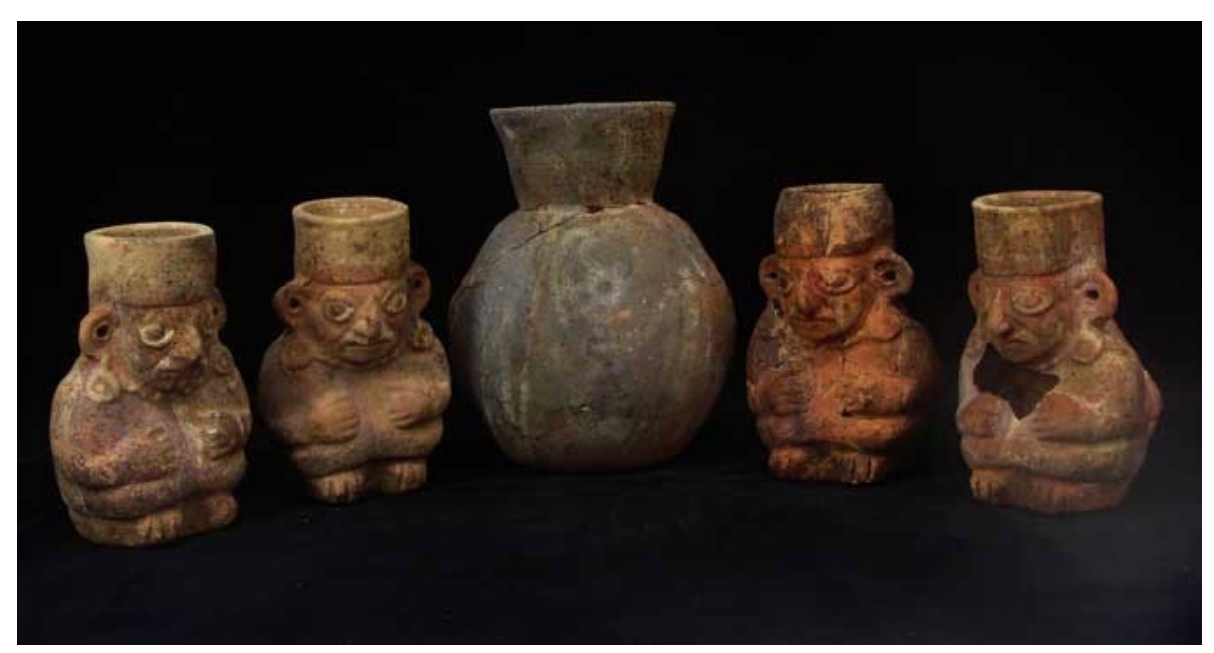

Figure 1. Face-neck Vessels from Tomb M-U1515, Middle Moche Period Source: San José de Moro Archaeological Project (Field Report), Peru.

With the flexibility in choice of craft, the Northern Moche were not confined to a single medium. Conversely, the Southern Moche reached an unparalleled level of sophistication in ceramic production, perhaps because they focused on the mastery of a single craft. At the Northern tombs of Sipán and burials at San José de Moro, thousands of face-neck/effigy vessels like the four in Figure 1 have been exhumed, but none match the refinement of the effigies found at the Huacas de Moche of the South.

\section{Northern Style}

The majority of face-neck vessels from the Northern Moche consist of a simple bulbous form in low relief with minimal to no detail of wardrobe, and a headdress that is integrated into the form of the vessel. One unique characteristic of Northern style face-neck vessels is the circular perforations made on either the earlobe or nostrils-these do not appear in any Southern style face-neck vessels. These nose and earlobe perforations may refer to Moche bodily adornments such as earspools or nose ornaments. Besides the circular cut-outs, there was little attention paid to post-assemblage finishing techniques; vessels appear to have been considered completed once the two halves were removed from the mold and joined together. The artist, or artists, responsible for producing these ceramic vessels did not smooth the clay body of inconsistencies when the clay was at its most malleable, moisture rich state. Nor did the creator/s burnish the vessels at the leather hard state (a low moisture stage when the clay is firm and perfect for adding carving and 
a paint). Burnishing, accomplished by rubbing a polished stone or bone tool over the surface, makes the vessel luminous and slick to touch (Koons 2012, 232).

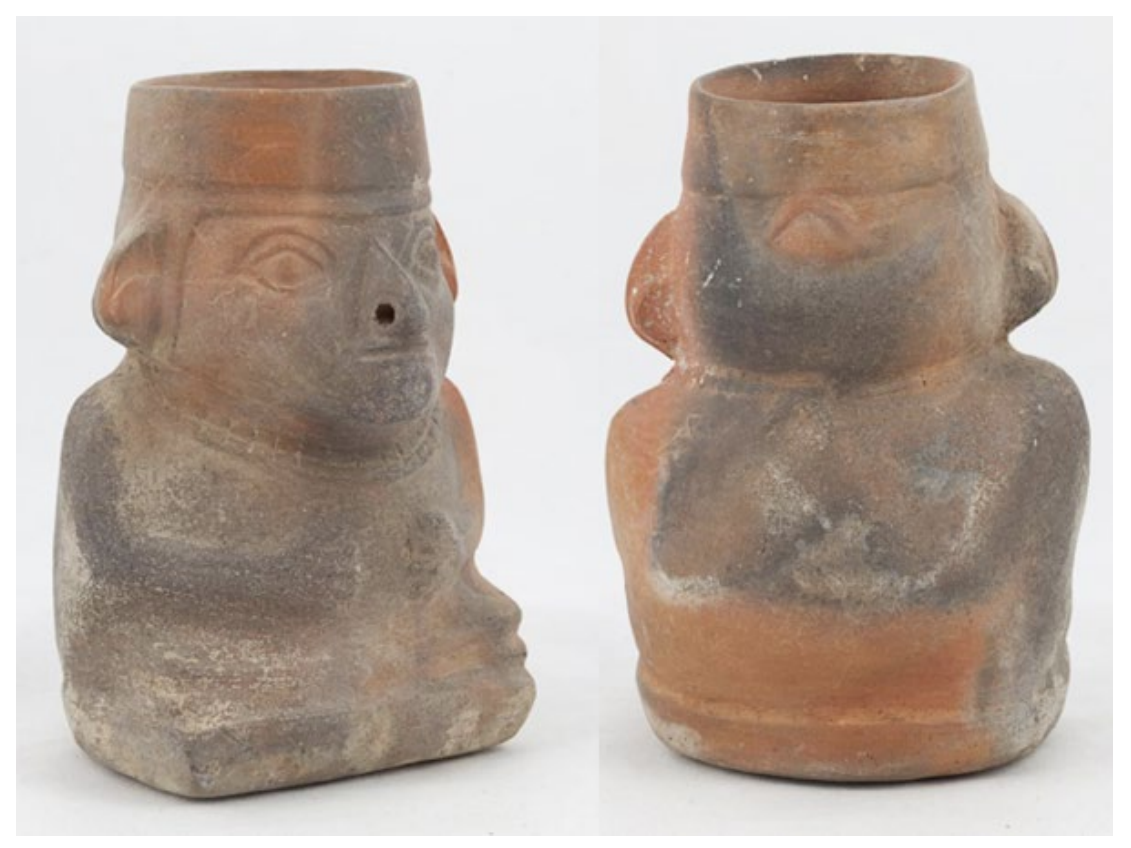

Figure 2. Front and Back View of Northern Style Face-neck Vessel. Middle Moche Period Source: Fowler Museum at UCLA (Online Database), Los Angeles, CA.

The Northern style face-neck vessel in Figure 2 has a simple shape with the headdress integrated into the form of the vessel. There is minimal attempt to depict clothing, though a necklace serves as a border between the head and body. The figure has only slight details in the legs, with no real distinctions to separate them from the rest of the body. The figure appears to be seated with its legs crossed, and the small protrusions of the knees can be seen on the front, bottom corners. The figure is also depicted with a solemn expression and appears to be in the praying stance as described by Walter Alva in other similar figures (Alva, 1994). The base is simple and rounded in the back with a flat squared-off edge along the front side. The rough texture and visible pores on the vessel indicates that the piece was not been burnished or smoothed of inconsistencies. Ultimately, it seems that the Northern Moche did not prioritize the aesthetic qualities of face-neck vessels. Instead they placed significance on the quantity of vessels produced, whereas for Southern Moche, quality was crucial. 


\section{Southern Moche Ceramics in the Middle Period}

The artistic identity of the Southern Moche is defined by elegant ceramics and monumental polychrome reliefs, seen at Huaca Cao Viejo and especially the sacrificial compound of Huaca de la Luna. The Huacas de Moche site is comprised of two architectural complexes, Huaca del Sol and Huaca de la Luna as well as a residential complex, which is of interest to my research. In the residential areas excavated at this site of the Huacas de Moche, a workshop consisting of fifteen rooms was dedicated to producing different specialized objects such as fine vessels and musical instruments. A second workshop was dedicated to the production of domestic vessels (Bernier 2010, 26). Hélène Bernier states, "Floor-intrusive kilns, grinding stones, matrices, molds, unfired pieces, pigments, as well as tools like potter's plates, scrapers, polishers, and burnishers were discovered in the ceramic workshops, suggesting that all steps of ceramic production were undertaken in situ". The Southern Moche regarded ceramics as an ideal visual medium to transmit Moche ideologies, so much so that they devoted multiple rooms in this complex to craft production.

\section{Southern Style}

The bulbous form and solemn expression of the face-neck vessels from Southern Moche are similar to those of the North but differ in terms of form, design, iconography, and finishing techniques. Face-neck vessels from the South were painted with contrasting slips in tones of red and cream to heighten the image's complexity. Slip, created from a mixture of mineral rich clays and water, is essentially paint for unfired ceramics; it was often reserved for fine ware (Koons 2012, 232). Slip application was used to create the illusion of garments and distinguish the adornments on the anthropomorphic figures.

Iconography is another element that distinguishes the South from the North. The face-neck vessels from the South are frequently personified as warriors. The ceramic warriors hold a mace and shield in each hand and wear large earspools and feline-pelt headdresses with chin straps. The back paws and tail of the feline rest on the back of the warrior figure and its face appears on the figure's forehead (Donnan 1978, 11). The ear spools may have been added post-mold assemblage as a part of finishing techniques. In terms of finishing details, the clay body is smoothed, wiped of textural imperfections, and carefully burnished. The level of threedimensionality and decoration in Southern Moche effigy vessels surpasses that of the Northern 
Moche. The headdresses on the face-neck vessels from the South appear to be separate vestments rather an integral part of the vessel. Another advancement in three-dimensionality of the South is the way the mace is often depicted as peeking over the shoulder of the warrior.

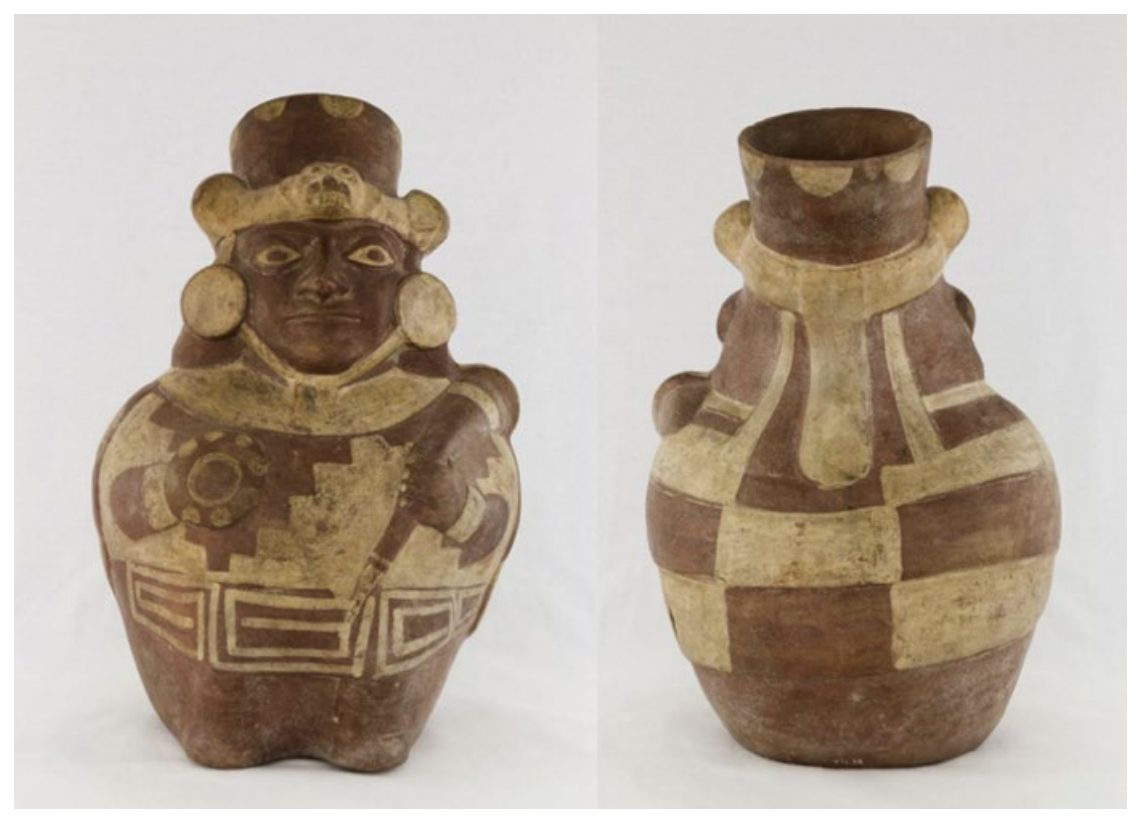

Figure 3. Front and Back View of Southern Style Face-neck Vessel Source: Fowler Museum at UCLA (Online Database), Los Angeles, CA.

The Southern style face-neck vessel in Figure 3 is highly three-dimensional and features a voluminous feline headdress and large earspools that protrude from the integral form of the vessel. The artist(s) used white slip to depict a geometrically-pattern tunic (different on the front and back) that appears to wrap around the body realistically. The figure stands upright with shield and mace in arms. The artist indented the base at the front of the vessel, where the feet would be, to show that the figure is standing on two different legs. The mace, which peeks over in the back view of the vessel, demonstrates the level of sophistication and realism that the southern Moche achieved in their ceramic works. These accessories were not merely carved into the existing vessel. They were beautifully sculpted and would often project into space. The texture of this vessel is smooth, as the Southern Moche were fond of using finishing techniques to enhance the quality of the piece. 


\section{Southern Moche Warriors at the Harn Museum of Art}

Figures 4 and 5 are both Moche face-neck vessels from the Harn Museum of Art, Gainesville, FL. While recognized as Moche, the provenience of these pieces has been unknown. By applying the stylistic distinctions it becomes clear that these vessels are from the Southern region. Figure 4 resembles the hands-on-torso face-neck vessel from the Northern Moche in Figure 2. While the depiction of the hands-on-torso pose is similar across regions, the finishing techniques of the two vessels make them distinct. The Southern style face-neck in Figure 4 has a smoothed, rotund body with skillfully detailed physical features. The arms are adorned with cream colored wristbands and the ears are decorated with two-toned earspools. In both Figures 4 and 5, each body part exists on a separate plane from the main vessel using crisp line contours. These vessels depart from the Northern style because they transcend simple vessel forms into the realm of sculpture. Their high degree of three-dimensionality elevates the status of the vessel from being a utilitarian form to a fine ware vessel.

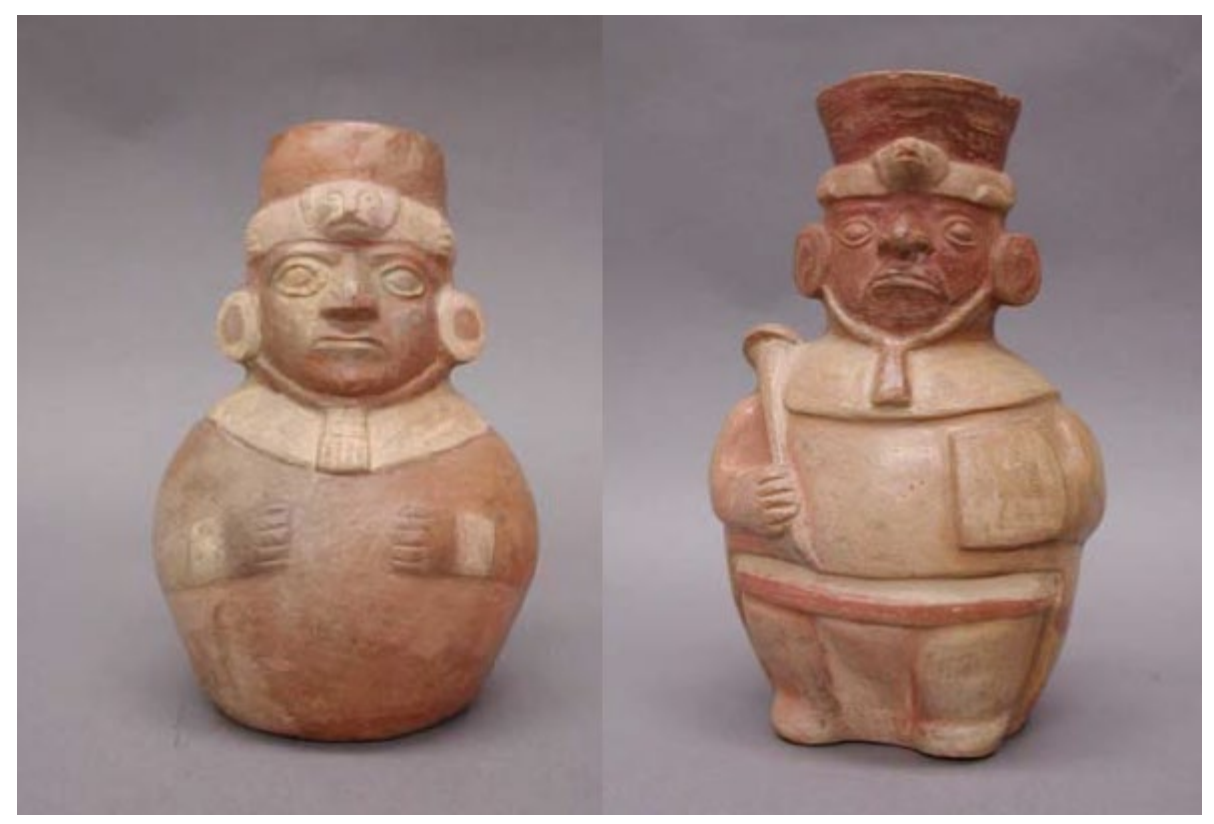

Figures 4 (left) and Figure 5 (right). Southern Style Face-neck Vessels Source: Harn Museum of Art (The Museum System), Gainesville, FL.

Figure 6 is a Southern style face-neck vessel from the Larco Museum, likely from the Chicama Valley as stated above. Figures 4 and 6 are almost visually identical, further supporting my 
contention that Figure 4 originates from the Southern region. The slight variations in vessel form and coloration may suggest that these vessels came from different Southern sites.

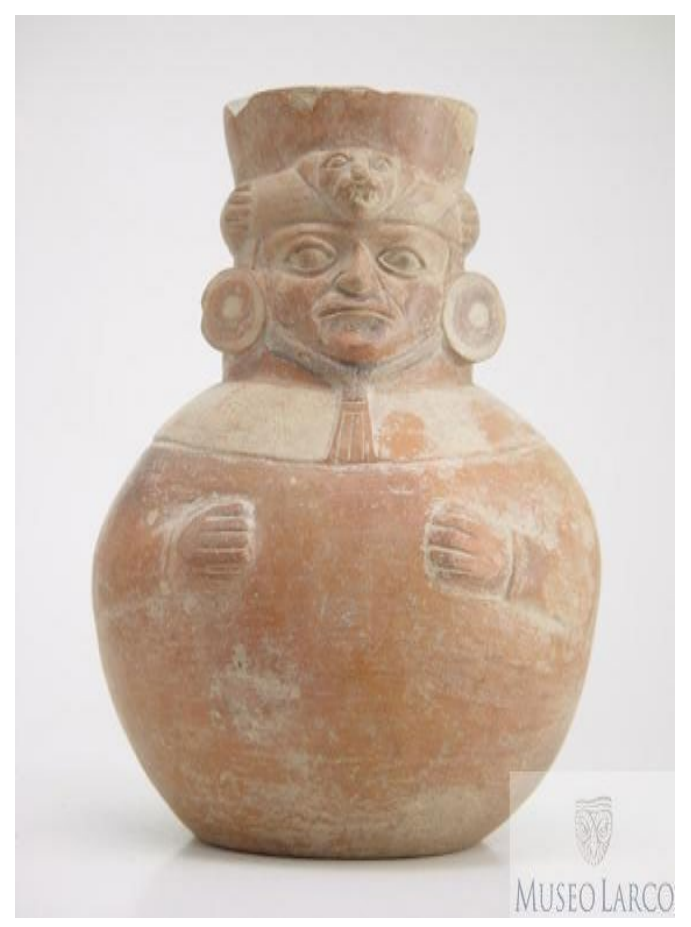

Figure 6. Southern Style Face-neck Vessel Source: Museo Larco (Online Database), Lima, Peru.

\section{Final Remarks on Northern and Southern Style}

Another consideration in terms of Northern and Southern style distinction is the way in which the two regions fired their ceramics. It seems as if the Southern Moche were particularly conscientious about the way each ceramic vessel was fired. Nearly all of the Southern style faceneck vessels are free of any black burn marks or carbon traces, which are usually caused in the process of firing. Conversely, the Northern Moche were less systematic in their firing techniques. Several Northern Moche face-neck vessels such as the ones included here have areas of discoloration caused by the way they were fired in the kiln.

Michele Koons states that "the Moche used kilns to produce both oxidized and reduced vessels. Oxidizing allows oxygen into the kiln during the firing process and produces buff to dark orange-red colored ceramics. Reducing eliminates the oxygen and produces gray to black ceramics" (Koons 2012, 233). 
While all of the vessels analyzed in this discussion are buff to dark orange-red in coloring, it is suggested that the Southern Moche face-neck vessels were fired in an oxygen rich environment, which produces rich colors. On the other hand, the Northern Moche face-neck vessels were fired in a slightly reduced oxygen environment with little control of airflow, which led to patches of gray and black discolorations on the vessels.

\section{Moche Funerary Practices from the Middle Period}

The highly complex and methodically engineered funerary practices and rituals of the Moche manifest in their materially rich burials. For each burial, the body was carefully prepared, wrapped in textiles; sometimes even placed in a coffin for the afterlife (Chicoine 2011, 528). Boot-shaped burials and simple pit tombs were used from the Middle to Late Moche periods (Castillo 2011; Koons 2012, 97). Items such as gourds, ceramics, bodily accouterments, metalwork, and tools or symbols of the deceased person's trade or status were placed in each burial. The contents of the grave would depend on the socio-economic status of the deceased (Donnan and Castillo 1992; Chicoine 2011, 528). The lavishness of burials existed on a vast spectrum to cater to people from all wealth backgrounds, and at least $76.8 \%$ of individuals were buried with at least one ceramic vessel (Millaire 2002, 131). Vessels were used for funerary offerings, holding organic materials believed to help the person transition into the afterlife. Common vessels for funerary offerings were the stirrup-spout bottle, bottle with lateral handle, canchero (corn popper form), florero (vase), cuenco (bowl), cántaro (pitcher), and jar (Millaire 2002, 131). Face-neck vessels are classified under the jar category. The functions of these vessels in real life were meant to match their functions in the afterlife (Jackson 2008, 39).

\section{Moche Mold Technology and its Influence in Funerary Practice}

The mold technology used by the Northern and Southern Moche accomplished several important goals for ceramic production in their society. Mold technology supported their religious beliefs in dualism, created ease in mass production, and expedited the production process, which was beneficial to funerary practices. As noted, the majority of Moche burials contained at least one ceramic object. Mold technology would have been essential and even necessary to accomplish the large-scale production of ceramics seen at the sites of Huaca's de Moche and Sipán. 
dualism. The use of molds in ceramic production established uniformity and consistency with each piece, which was crucial to Moche beliefs in dualism. The Moche celebrated dualism as complementary pairs, and even by the power of opposing forces like the sun and moon (Holmquist 2013, 66). The Moche made pairs of items in visual oppositions such as ceramic vessels of opposing colors - black ware versus terracotta with red and cream slip. From the tombs of Sipán, there are pairs of identical back plates and peanut necklaces made of contrasting silver and gold. In the South, the complexes of Huaca del Sol and Huaca de la Luna represent opposing powers and the structures themselves were designated for different purposes. Huaca del Sol is an eight-step platform identified as a place of funerary importance, whereas Huaca de la Luna served as a sacrificial compound where thirty-five to forty-five skeletons were found scattered in a courtyard (Bawden 1996, 227-232). Also found at the Huacas de Moche were two identical effigy vessels of skeletons. This pair of vessels is unique because one was fired and the other was left unfired. These intentional differences suggest a complex form of duality that implies that their physical presence alone was more important than actual functionality (Bourget 1996, 52; Jackson 2008, 40).

molds. Despite the distinctions between Northern and Southern Moche ceramic styles, mold technology was a shared technique in ceramic production for funerary purposes. For the North, molds were essential for mass production. In the South, molds were utilized to create refined identical objects to express notions of dualism. In order to create a mold, it would first require a matrix to be made. The matrix represents the desired completed product, which serves as a guide for future reproductions. The matrix would be crafted by hand and the form would be perfected in order to create the best product from which a relief could be extracted. Once the matrix was completed, it would be used to create a mold by pressing slabs of clay onto the fired body. Subsequently, the reliefs taken from the matrix are fired-this is the mold. Fresh clay slabs were simply pressed into the mold, removed when stiff and the two halves joined and fired to create the final product. While molds could consist of multiple compartments, the most common was the two-part mold. Basic two-part molds would have been used to create items such as the faceneck vessel. From a single mold, multiple objects could be created. 


\section{Conclusion}

This research relies immensely on interdisciplinary research, incorporating my studies in art history, archaeology, anthropology, and studio arts. By conducting this type of multi-disciplinary inquiry, better ideas about cultures can be formed. While many popular museums worldwide own at least one Moche object, they are never categorized by Northern or Southern style. Moreover, when reading about Moche art it is mentioned that there are "slight regional differences" between Northern and Southern Moche art but these stylistic distinctions are never explicitly stated. By understanding these stylistic distinctions between Northern and Southern face-neck vessels, the role of ceramics in funerary practices and rituals across the two regions can be recognized.

\section{Acknowledgments}

Thank you to Dr. Maya Stanfield Mazzi for her endless support and mentorship, as well as San José de Moro Archaeological Project, The Harn Museum of Art, The Fowler Museum, and Museo Larco for graciously allowing me to examine works within their collections.

\section{References}

Alva, Walter, and Donnan, Christopher B. 1994. Royal Tombs of Sipán. Los Angeles, CA: Fowler Museum of Cultural History, University of California.

Bawden, Garth. 1996. The Moche. Cambridge, Mass: Blackwell.

Bernier, Hélène. 2010. Craft Specialists at Moche: Organizations, Affiliations, and Identities. Latin American Antiquity 21 (1): 22-43.

Bourget, Steve. 2006. Sex, Death, and Sacrifice in Moche Religion and Visual Culture. 1st ed. ed. Austin: University of Texas Press.

Castillo, Luis Jaime, and Christopher B. Donnan. 1994. Los mochicas del norte y los mochicas del sur. Vicus: 142-181.

Castillo, Luis Jaime, and Uceda, Santiago. 2008. The Mochicas. In Handbook of South American archaeology: 707-729. New York: Springer.

Chicoine, David. 2011. Death and Religion in the Southern Moche Periphery: Funerary Practices at Huambaco, Nepeña Valley, Peru. Latin American Antiquity 22 (4): 525-548.

Donnan, Christopher B. 2003. Moche Portraits from Ancient Peru. Austin: University of Texas Press.

Donnan, Christopher B. 1978. Moche Art of Peru: Pre-columbian Symbolic Communication. Rev. ed. Los Angeles: Museum of Cultural History, University of California. 
Donnan, Christopher B., and Luis Jaime Castillo 1992 Finding the Tomb of a Moche Priestess. Archaeology 45(6):38-42.

Donnan, Christopher B., and Carol J. Mackey. 1978. Ancient Burial Patterns of the Moche Valley, Peru. Austin: University of Texas Press.

Holmquist, Ulla. 2013. "The Symbolic Language of Ancient Peruvian art.” In Peru: Kingdoms of the Sun and the Moon., eds. Victor Pimentel, Luis Eduardo Wuffarden. ed., 66-73. New York: Distributed in the United States and Canada by Harry N. Abrams; Montreal Museum of Fine Arts.

Jackson, Margaret A. 2008. Funerary contexts. In Moche Art and Visual Culture in Ancient Peru., 39-40. Albuquerque: University of New Mexico Press.

Koons, Michele. 2012. Moche Geopolitical Networks and the Dynamic Role of Licapa II, Chicama Valley, Peru. PhD Diss. Harvard University.

Millaire, Jean François. 2002. Moche Burial Patterns: An Investigation into Prehispanic Social Structure. Oxford, England: Archaeopress. 